\title{
More Than a Teacher: Understanding the Teacher-Learner Relationship in a Public High-School in South Africa
}

\author{
Leza J Soldaat ${ }^{1}$ \\ ${ }^{1}$ Sociology and Social Anthropology, University of Stellenbosch, Stellenbosch, South Africa \\ Correspondence: Leza J Soldaat, University of Stellenbosch, Stellenbosch, South Africa. E-mail: \\ lezasoldaat@ymail.com
}

Received: March 15, 2019 Accepted: April 9, 2019 Online Published: April 26, 2019

doi:10.5539/jedp.v9n1p77 URL: http://doi.org/10.5539/jedp.v9n1p77

\begin{abstract}
Teaching is considered a caring occupation due to the nature of the interaction between teachers and learners (Hocschild, 1983). Care giving can be a demanding task, however, emotional labour invested in the occupation with regards to their relationships with learners - contributes to job satisfaction, commitment and be emotionally rewarding. The proximity or distance of these relationships are dependent on five emotional geographies, namely socio-cultural, moral, professional, physical, and political relatability (Hargreaves, 2001). This paper draws on a case study of teachers at a former Model C high-school in South Africa to examine the formation and development of relationships formed between the teacher and learner. The article suggests that teachers adopt three additional roles outside that of teaching. These roles, the coach, counsellor, and parental figure, foster emotional understanding (Denzin, 1984) between the teacher and learners, which creates a positive classroom climate. These roles are deemed necessary for the fulfilment of successful relationships with learners. However, there are challenges which teachers face when attempting to develop these bonds with learners, which include a negative classroom climate, socio-cultural distance, and sexual harassment - faced by women teachers.
\end{abstract}

Keywords: caring teaching, emotions, emotional labour, emotional geographies, teacher-learner relationships

\section{Introduction}

The social importance ascribed to education — and by extension the school system through which it is provided suggests that education offers individuals what the family or community cannot provide; that is, the necessary linguistic and cultural competences required to work and exist in society (Bourdieu, 2003). Teachers, who are active agents in the education system, have the necessary instruments to provide learners with knowledge and distribute to them the necessary socio-cultural tools to help learners create a 'better future for themselves' (Bourdieu, 2003; Lareau, 2011). As compensation for teachers' participation in the education system, they receive a wage. In addition, it is assumed that the teaching position is a "care occupation" in which the learner benefits significantly (Folbre, 2013). As a result of this classification, there is a perception that the classroom is naturally a caring environment and that there is an element of care in the teacher-learner relationship. Teachers engage also with emotional labour which refers to the process by which workers are expected to manage their feelings (Hochschild, 1983). In South Africa, little research has been conducted on the emotional labour performed by South African teachers in the fulfilment of their official, and sometimes non-official, duties. This has led me to my primary research question: How do teachers reflect on their relationship with their learners? By exploring and understanding the relationship between the teacher and learner- as perceived by the teacher - findings revealed that the rewards derived from developing this relationship outweigh the negative effects of performing emotional labour.

\section{Literature Review}

\subsection{Power Relations}

Teachers are viewed as agents who act on behalf of the state in that they have some authority over learners (Bourdieu, 2003; Lareau, 2011). Power relations exist in the relationship between teachers and learners as well as between teachers and the state. Power is a relational construct exercised in a social arena or a structured system of social positions (Ostrom, 2005; 2010; 2011). Within the social arena or system, different forces exist, which all interact in unique ways, thus the concept of power relations is used to deconstruct how certain forces interact with 
others. The mechanism that is power regulates thoughts and behaviours of social actors through subtle means and is under constant surveillance (Foucault, 1975; 1976a; 1976b; 1982). Power is exercised through disciplinary means in a variety of institutions such as the school (as the state has power [authority] over the school). Emotion is embedded in power relations and is inherent to the development of social norms and emotion talk (Reygan \& Francis, 2015). Therefore, in the social context, emotional rules are a reflection of power relations as they are a form of social control.

Emotion rules "are techniques for the discipline of human difference in emotional expression and communication" (Zembylas, 2002: 200). The rules portray the ways in which the body and self are governed and controlled (Foucault, 1976a; 1976b) and become a reflection of power relations in a space where some emotions are permitted, and others are not; emotions like frustration tend to not be suitable for external display (Zembylas, 2002; 2005; Steinberg, 2008; Yin \& Lee, 2012).

According to the South African Constitution, "children has the right to family care or parental care, or to appropriate alternative care when removed from the family environment" (Republic of South Africa 1996: 28(1) (b)). In addition, the common law principle, in loco parentis, refers to a teacher or other adult responsible for children (in place of a parent) and that they have a legal duty to ensure the safety of learners in their care. "[Teachers] as persons in loco parentis are vested with special status that empowers them to act authoritatively in terms of the law" (Prinsloo, 2005: 9). Teachers have both delegated powers (delegated by the principal of the school) and original powers (originating in the common law) over the learners during school hours and extramural activities (Prinsloo, 2005; Prinsloo, 2006).

In South Africa, teachers need to abide by the common law principle, in loco parentis. This encompasses, according to Maithufi (1997), two coextensive pillars. The first is teachers' duty to care and the second is their duty to maintain order at the school. The former implies looking after the learners' physical and mental wellbeing and the latter implies teachers' duty to discipline learners. Despite these duties, more specifically the duty to care, what the common law principle and first pillar fails to acknowledge is what caring means for the teacher and how is it executed.

\subsection{Emotions and Care}

The role of emotion in the context of the teaching practice is still largely unexplored in the South African context (Reygan \& Francis, 2015). Emotions are considered from a socio-cultural perspective as they are constructed by social interactions and institutional structures that are managed within certain constraints. In addition to this perspective, emotions are constructed within their cultural context, where actions and practices constitute and construct our own understanding of the world; this discourse takes into consideration the power relations that are inherent to emotion talk.

The social context in which teachers find themselves determines what emotions are likely to be produced (Kemper, 1993; Hargreaves, 2001). People live in different social contexts and socialise differently. This socialisation gives individuals a sense of what is natural to them. "Individuals tend to see their society's social arrangements [status, privilege, and similar social rewards] as legitimate" (Laureau, 2011: 275). Bourdieu terms this 'normalisation' as habitus. Individuals use the habitus at their disposal to operate in a number of social spheres, including culture, society, and for one's future. "Bourdieu stresses that the differences in habitus give individuals varying cultural skills, social connections, educational practices, and other cultural resources, which then can be translated into different forms of value (i.e., capital) as individuals move out into the world" (Laureau, 2011: 276).

Teaching is considered a profession that is caring and passionate in nature and is shaped by the teacher's personal disposition, moral commitment and/or private virtue (Hargreaves, 2001). O'Connor (2008) identifies caring teaching through three dimensions: professional, performative, and philosophical/humanistic. In the first dimension, teaching is seen as an acting job in which teachers maintain their positive feelings, act professional, and maintain their sense of self. However, this has emotional implications (such as burnout). Teachers are in constant negotiation with themselves, by either maintaining professional distance or their personal desire to 'go the extra mile' (O'Connor, 2008). In the second, performative, dimension teachers are in constant negotiation in choosing 'how much' they should care or what is the 'right way' that they should care. The difficulty, of course, is that caring cannot be quantified. Nonetheless, there remains a professional distance between teachers and others in the space (colleagues, parents and learners) that is regulated by institutional constraints ( $\mathrm{O}^{\prime}$ Connor, 2008). In the third dimension, teachers adopt a humanistic philosophy of teaching. Teachers "invest in the values that they believe their teaching represents" (Zembylas, 2003: 213): the caring work they do is grounded in a particular way of thinking and is the outcome of conscious decisions. This stance differs amongst each teacher because of their various orientations towards humanism, which is why the conscious decision to take on a particular way of caring 
may not be shared among colleagues (O'Connor, 2008).

The care relationship between teachers and learners has two sides, namely, the positive and negative aspects of emotional labour. The relationship between the two can become a source of professional satisfaction whereby teachers see the fruit of their labour and enjoy their emotional work as carers, but also experience negative emotions such as anxiety, disappointment, anger, or emotional strain. This forces teachers to observe a type of emotional dissonance, where what they feel is not reflected in what they display, potentially leading to self-alienation or emotional disorientation (Zembylas, 2005; Isenbarger \& Zembylas, 2006).

\subsection{Emotional Labour and Rules}

Emotional labour is the process by which workers suppress and manage the true nature of their feelings and generate and/or portray a desirable emotion in a specific context (Hochschild, 1983). According to Hochschild (1983: 147), jobs that require emotional labour have three common characteristics: 1) face-to-face contact between the employee and the client; 2) the employee is required to produce an emotional state in the client; 3 ) the employer is able to exercise a degree of control over the employees' emotional activities.

For Hochschild (1983), emotional labour is a primarily negative concept, as it requires trading a part of the self in order to motivate one's customers/clients within an organisation in exchange for the employee's job security and financial rewards. Hargreaves (2001) argues that Hochschild (1983) ignores the pleasure that some derive from performing emotional labour; "[Hochschild] perhaps overestimates the exchange value of emotional labour (as in the profit value or emotional "selling out"), at the expense of the use value of such labour (what the labour creates and recreates in oneself and in others) as an act of sincere emotional giving" (Hargreaves, 2001: 1074).

Emotional rules guide employees on how much they should or should not be involved when interacting with clients (Hochschild, 1979, 1983, 2003, 2011), as these aid "emotion work by establishing the sense of entitlement or obligation that governs emotional exchanges" (Hochschild, 1983: 56). Emotional rules refer to "the social guidelines that direct how we want to try to feel [which] may be describable as a set of socially shared ... rules" (Hochschild, 1979: 563) and take place through the policing and management of emotions as 'appropriate' or 'inappropriate'; classifying the former as normal and the latter as deviant (Foucault, 1983).

Five emotion rules are suggested by Winograd (2003), similarly to Yin and Lee (2012), for employees within the teaching occupation. First, teachers should display affection for their learners. Second, teachers should display enthusiasm and passion for their subject(s) and their learners. Third, teachers should avoid displaying extremely negative emotions such as anger. Fourth, teachers should love their work, and lastly, they should display a sense of humour in light of their own and learners' errors.

Care-giving can be a demanding task, however, with regards to the teaching occupation, emotional labour can contribute to teacher satisfaction, commitment and be emotionally rewarding (Wharton, 2009; Isenbarger \& Zembylas, 2006). Caring is not only a feeling concerning the well-being of learners, but it is also an emotional investment. This investment is placed in the relationships that teachers form with learners.

\subsection{Emotional Geographies}

Emotions underpin teacher-learner relationships and are central to the meaning of this interaction. As a result, Hargreaves (2001) states that emotional geographies are considered to "describe the patterns of closeness and distance in human interactions" (1056). Hargreaves $(2001 ; 2005)$ draws on Denzin's (1984) theoretical framework on emotional understanding to analyse teachers' emotions; this refers to the process of understanding one another's lived experiences (Denzin, 1984: 137). Emotional understanding thus fosters closeness between parties, i.e., teacher and the learner, and conversely emotional misunderstanding creates social distance between them. The five emotional geographies Hargreaves (2001) suggests are namely: socio-cultural, moral, professional, physical, and political closeness/distance.

Socio-cultural closeness/distance addresses the social and cultural differences among individuals who are in the same space. Teachers find themselves in spaces where individuals belong to various socio-cultural groups which could cause teachers to become distant from their learners. In these cases, where the teacher does not belong to the community in which their learners come from, they often ascribe stereotypical characteristics to the group (Hargreaves, 2001; Francis, 2017). Emotions are bound to teachers' personal purposes. Therefore, moral closeness/distance, for example, depends on teacher satisfaction and pleasure guided by achievement and success of their own work and of learners' performance (Steinberg, 2008; 2013a; 2013b; 2015). The third emotional geography is professional closeness/distance. Teachers are pushed to adopt a 'classical professionalism' approach which means remaining professional in order to avoid emotional entanglements. The fourth emotional geography is physical closeness/distance. In order to establish emotional relationships, a close proximity is required and a 
"measure of intensity, frequency, and continuity in interaction" (Hargreaves, 2001: 1070). The fifth and final emotional geography is political closeness/distance, which happens to be intertwined with individuals' experiences of power and powerlessness. "A very large number of human emotions can be understood as responses to the power and/or status meanings" (Kemper, 1995: 125 in Hargreaves, 2001). An elevated status, for the teacher, increases their power which makes them feel more secure.

An atmosphere of care and acceptance proved to be important in establishing a caring relationship (Isenbarger \& Zembylas, 2006). By ensuring this classroom climate, the teacher-learner relationship is enhanced. However, it is worth emphasising that teachers have choice as to whether or not they want to care for learners, and this choice is influenced by their convictions about the role of a teacher and the degree to which they value the need to sustain positive teacher-learner relationships (O'Connor, 2008). Creating positive relationship makes for a rewarding teaching experience (Zembylas, 2004b). According to Lortie, psychic rewards "rotates around classroom events and relationships with students; the cathexis of classroom life underlies much what teachers feel about their work" (1975: 187). These rewards are gained from working with learners, which include gratifying graduates, public performances and celebrations, and the success of individuals.

\section{Research Design and Methodology}

\subsection{Participants}

The sample consisted of five participants of which four were women and one man. Participant one, Ms. Abrahams (Note 1), taught Afrikaans and at the time research was conducted [2017] she had been teaching for three years making her relatively new at the school. Participant two, Ms. Conley, has received training in both Biology and Mathematics, but teaches Mathematics at Hullbeck High (Note 2). She is employed part-time in order to spend more time with her family (prior to 2016 she taught full-time). My third participant, Mr. Jonathan, has been teaching Life Orientation and Geography at Hullbeck High for eleven years (prior to this he taught at a youth centre correctional facility for twelve years). Participant four, Ms. Malik, has been an English teacher for twelve years including Hullbeck High as of 2013. In 2017, she started teaching History as well. My fifth participant, Ms. Fenty, did not conduct an interview, however in 2016 she revealed to me that she will no longer teach English at Hullbeck High due to immense pressures.

\subsection{Sampling Procedures}

Ethical clearance was granted from the Research Ethics Committee of Stellenbosch University and the Western Cape Education Department to conduct research at Hullbeck High. Thereafter, I set up a meeting with the principal of the school to discuss the particulars of my research. He introduced me to the teachers in the staff room where I was given the opportunity to discuss the objectives of my research. I was approached by multiple participants, but only five committed in the ongoing study. As a former student of the school, I did not find any difficulties gaining access and navigating the school space. Therefore, my position at the school was a researcher and former student.

\subsection{Research Design}

A case study was conducted using qualitative research methods. It was to understand the realities of the teachers and "the subjective world of [their] experiences" (Cohen \& Manion, 1994: 36). Focus was placed on a small group of participants in order to provide an in-depth analysis of their accounts. Five teachers committed to participating and one participant left Hullbeck High in 2017; therefore, only observations recorded in 2016 were available for this teacher. My main source of data collection with this participant, Ms. Fenty, was video recordings which she provided. Over 55 hours were spent with participants (observations) and approximately 4 hours' worth of interviews were recorded, transcribed, and a thematic analysis was used.

Two types of observations were conducted: detached observer (inside the classroom) (Dreyer, 1998) and participant observations (outside of the classroom in areas such as the smoker's corner, the staffroom, and on the sports field). The latter was conducted mainly with the teachers outside of the classroom or when they were 'free', i.e., when they did not have a class to teach but potentially other work to complete. The second form of data collection was through unstructured interviews in order to gain insight on their thoughts, on the experience of being a teacher, and their relationships with learners. Interviews were transcribed by myself in order to portray correctly what they said and how they said it. This provided me the opportunity to transcribe what the participants said at the time while simultaneously understand the social context in which they exist, i.e., the interviews took place at the school. Many interviews were conducted in the mother tongue of most participants, Afrikaans, or a combination of English and Afrikaans, which I translated. This could only be understood from someone with the knowledge of colloquial use of both languages, as in my case. Interviews were also compared with my observations in order to preserve the sequence of events. 


\subsection{Data Analysis}

The above-mentioned methods were used in order to uncover the various ways in which teachers invest their time and energy in teaching. A selective approach was followed in order to identify thematic aspects that address my research questions (Van Manen 1990). General themes were identified in both my observations and interviews (Silverman 2011) so I could identify and categorise (code) different expressions, thoughts, and emotions. I created my own labels, which included 'teaching' (teaching style, professional identity, and teaching background), 'interaction' (any form of interaction that takes place with learners, colleagues, and myself), 'atmosphere' (classroom climate), and 'emotions' (as experienced and expressed by the teacher). This was done to facilitate analysis of my observations. For my interviews I used the same approach but included 'personal' as a theme in reference to teachers' identity and personal lives (Silverman 2011). During this analysis, my focus remained on addressing the relationship between learners and teachers, which I maintained by frequently referring to my research questions and aligning my thoughts accordingly. Once I had identified my different codes, my data was analysed thematically (Bryman 2012). The themes that were identified in my coding process were used to analyse my data.

\subsection{Painting a Picture, Providing Context}

Hullbeck High is a co-educational multicultural dual-medium high-school situated in the picturesque Breede River Valley in the Western Cape (Note 3). This school was chosen due to their focus on extra-curricular activities (Note 4), driving the assumption that teachers invest more time in these activities than in most of the other schools in the area. The school was established in 1873 as a boy's high-school with 78 learners on its register. In 1876, its counterpart, a girl's high-school, was established with 16 learners on its register. By 1972, with the increasing popularity of co-education, the two schools merged on the grounds of the boy's school. The girls school building was transformed into an art school called Hugo Naude Art Centre. A different branch - Hullbeck East High School - was established in 1941 as a technical college at a separate location. In January 1992, the three institutions merged and rebranded as Hullbeck High.

In the South African context, Hullbeck High is known as a former Model C school, a term used to describe former Whites-only government schools despite the post-apartheid (Note 5) government abolishing this term. During apartheid, state-funded - or public — schools were segregated based on racial categories and had separate educational departments allocated to each group (Teeger, 2015). Learners attending White schools received the best resources from the state whereas African schools received very little resources, resulting in extremely poor learning conditions. The label, Model C, came to the fore during negotiations in the early 1990s between the outgoing apartheid government and incoming ANC-led administration, whereby white schools were given the option to become desegregated - by accepting children of colour and thus determining their own admission policies - and continuing to receive state funding for staff, or becoming private institutions with no or reduced funding from the state (Carrim, 1998; Hofmeyr, 2000). In 1996, a single education system was created (Teeger, 2015; Republic of South Africa, 1996).

\section{Social Roles Teachers Adopt}

Teachers define themselves through the different roles they play in their professional lives over and above their actual employment duties (Nias, 1989; O'Connor, 2008) which is done by emotionally engaging with their learners outside of the classroom through offering support, care, and compassion (Oplatka, 2007). These roles, within their professional lives, are termed 'non-work', as teachers do not benefit from them financially and they do not form a technical requirement of their job (Forrester, 2005: 274).

Teacher's take on three additional roles that they deem necessary for the development of positive relationships with learners. It is through these roles that teachers come to care for their learners as well as how they perceive their relationships with them. The roles teachers adopt are of coach, counsellor, and parental figure. The roles typically form over time and evolve depending on how teachers use them, which encompasses multiple facets.

\subsection{Non-Work: Taking on the Role of the Coach}

The most common role was the coach. Many teachers adopt this role to some extent, be it of a sporting or cultural activity. In South Africa, it is classified as non-work in the Employment of Educators Act (Note 6), as it is a voluntary, unpaid contribution.

While little research has been conducted on the coaching role and how it fosters a stronger relationship between a teacher and their learner, it remains an important role as coaching generally helps to establish deeper emotional bonds. The classroom can largely become a space where teachers are perceived, by the learner, as a rational agent of the school instead of an emotional one, which may become a source of negative emotion for the teacher when 
learners harbour unpleasant sentiments about the school (Hargreaves, 2000).

Hullbeck High offers a wide variety of extra-mural activities, which creates the opportunity for learners and teachers to form a relationship even greater than in other schools which do not offer as much activities. As a result of this opportunity, stronger bonds are formed between the two parties. This role mainly comes into play mainly during official school-hours, apart from the Physical Education teacher as seen in the case of Mr. Jonathan. Coaching is, in this case, conducted during official school hours and forms part of Life Orientation (a compulsory subject offered in South African schools).

These bonds can be transferred into the classroom space, thus enhancing the experience for all. By taking on the coaching role, teachers enjoyed the opportunity to view learners in a different light and observe the different social dynamics between learners. However, coaching is a time-consuming and physically draining activity for teachers. Despite this complaint, teachers expressed that coaching is done in a space where they can "laugh together [and] cry together". The engagement between the two parties outside of the space results in learning from each other's lived experiences. As a result, it translates in this space when teacher's draw on their learners' experiences; "their real life, you can apply on things that might be very abstract in the classroom" (Note 7).

\subsection{Reacting in a Time of Need: the Counsellor Role for the Wellbeing of Learners}

The most prominent role teachers adopt for the well-being of learners is the counsellor. Teachers take on this role as "many learners [have] troubling issues in their lives and often [have] no one else to rely on for support" (Brown \& Dickinson, 2014: 67). Teachers are motivated by their humanistic/philosophical values and beliefs, which is beneficial for the learners as it tends to their emotional and mental well-being. The role mainly comes into play when the situation requires teachers to do so, often in a space outside of the classroom.

The prominent moment this role came into play was when Ms. Malik had to intervene when a learner (not from her classes) had an anxiety attack; I had to intervene myself in this case. A group of learners came rushing in the classroom, from the bathroom, frantically asking for her aid to which she responded with urgency. Teachers experience a philosophical/humanistic dilemma as they are in negotiation with themselves about whether they are doing the right thing or not (O'Connor, 2008). Mr. Jonathan, as seen in my observations, has experienced a similar situation with a student who experienced an anxiety attack (Note 8).

Another moment where this role came to the fore was when Mr. Jonathan facilitated a conflict-resolution group to discuss and resolve the tension in the classroom between the learners (Note 9). This is a unique role as LO teachers are daily faced with the individual issues of learners (Brown \& Dickinson, 2014). Similarly, to Brown \& Dickinson's (2014) study on LO teachers, they opened a space for learners to approach them if they had an issue. This demonstrates care by helping the learners with their personal issues/problems; or care as a responsibility for learners (Nias, 1989). By ensuring a positive classroom climate, the learners are able to achieve their academic purposes and emotional needs better, as well as maintaining a positive well-being (Zembylas, 2004a).

4.3 "Love them Like They Your Own Children": Becoming the Parental Figure Inside and Outside the Classroom

The role directly expressed to me by participants was the parental figure. Teachers would often refer to themselves as the "mother" of the class or the "father" figure and refer to their learners as "my children/my kids" (Note 10). While teachers still considered themselves the authoritative figure in the classroom, this was not done in a rational way but was rather tied up with emotion. The relationship between teachers and learners is typically marked by mutual respect and a sense of responsibility in that teachers are invested in their learners' progression and learners feel committed to appreciating their teachers' efforts by succeeding. Teacher's care about the learning performance and emotional status of students. Because of this commitment and investment, teachers often compare themselves to be a parental figure to learners, which is a reflection of the caring ethics of the teaching profession. Yin and Lee (2012) describe that this indicates that teaching is 'heart-consuming' labour that reflects the emotional labour of teaching. By conducting heart-consuming labour, teachers take on the authoritative caring figure motivated by discipline (Yin \& Lee, 2012). Ms. Malik even points out that "[she] get[s] to love them like they are [her] own" (Note 11).

Teachers are expected to care about their learners and enforce strict rules; their strictness highlights the care for their learners (Zhang \& Zhu, 2008). Adopting this parental figure role in the classroom showcases that teachers' care for their learners' emotional well-being and academic performance, as seen in the case of Ms. Conley who expressed that those who are more responsible and serious about their work, appeals to her (Note 12). Interestingly, this is often done through discipline, as this relationship is reliant on authority, responsibility, and morality (Yin \& Lee, 2012; Gao, 1998). Despite this, in loco parentis requires teachers to take responsibility for the well-being of their learners. 
Ms. Abrahams, as seen in observations and our interview (Note 13), takes on the parental role with her register [admin] class due to the close and personal relationship they formed inside and outside the classroom. Therefore, this indicates a strong emotional understanding between her and the learners. She reveals, in our interview, that she had to "fight" for her learners to remain her register class in 2017. "[Learners] are the main 'object' that teachers feel strongly about" (Steinberg 2013: 24). Golby (1996) quotes how teachers attached 'possessive' feelings about their learners; which could be seen with Ms. Abrahams' relations with her register class. In reflecting about the rewards of teaching, she referred back to her register class; I think it is the biggest reward that I can share my life with them and that they can share with me (Note 14). This relationship, therefore, is a source of professional satisfaction; she enjoys caring for her learners.

\section{Challenges That Hinder the Formation of Bonds}

Relationships form over time and the cultivation thereof fosters a deeper and more personal relation between those involved. The formation and development of these relationships, or "bonds" (Note 15), play the biggest role in the teacher's attitude towards teaching and learners' academic success. Maintaining these relationships requires a shared understanding of emotions (Denzin, 1984) and "a predominantly positive emotional state" (Steinberg, 2008). Teachers are not required to form bonds however, by doing so teaching becomes more rewarding and a source of professional satisfaction (Zembylas, 2004b). This, therefore, is the reward of the emotional labour invested in the teaching profession. These rewards make up for the negative effects of emotional labour, such as burnout (Hargreaves, 2001; Zhang \& Zhu, 2008). However, when teachers experience negative emotions over time, their commitment towards developing bonds with learners and teaching in general fades (Steinberg, 2008).

Teachers are faced with various challenges daily when attempting to create a positive and productive relationships with learners. These challenges include the climate of the classroom (which teachers sometimes struggle to regulate), socio-cultural backgrounds (values of the school and of the learners differ), and sexual harassment (mainly experienced by woman teachers).

\subsection{Keeping 'Order': Classroom Climate}

In the classroom, learners are required to engage in consistently positive emotional experiences. This, in turn, contributes to the stimulating climate of the classroom, which forms the foundation of the relationship between teachers and learners, and is necessary for motivating individuals to learn (Meyer \& Turner, 2006). However, the stance that the teacher takes on in the classroom could threaten this climate if they, for example, adopt a classical professionalism approach.

In order to ensure a positive classroom climate, emotional understanding needs to exist between the teacher and learners. From observations, it is clear that teachers use a facade to ensure that their emotions do not cloud their judgment and to ensure that the classroom remains a positive teaching and learning environment (Yin \& Lee, 2012). However, to remain completely distant from learners creates potential for emotional misunderstanding and could, in turn, dampen the classroom climate. The environment of the classroom reflects the emotional experiences of the teacher and learners, and if the environment is negative, as seen in my video observations of Ms. Fenty's classes, it is a reflection of the unpleasant emotional experiences of both parties (Meyer \& Turner, 2006).

Ms. Fenty provided me with video recordings of her various classes in 2016. In my observations of these videos, learners did not approve of their being recorded, which sparked a lot of debate in the classroom. This resulted in tension between the learners and the teacher. The different expressions of negative emotions from both parties made the environment quite unpleasant and interfered with the teaching and learning process. In addition, this negative environment hinders the likelihood for bonds to form. There seems to be moral emotional misunderstanding between Ms. Fenty and her learners. It is observable that she experiences frustration and stress, which is due to her feelings of authority being undermined and her sense of purpose perceived as being challenged. This is one of the few ways in which emotional labour could contribute negatively and the teacher would need to be in constant negotiation with themselves.

\subsection{Discrimination and Prejudice: Socio-Cultural Background}

Bonds are formed in a specific cultural context, with individuals from different socio-economic backgrounds. However, it is a challenge to really know and meaningfully understand all learners and their backgrounds; it can be daunting for teachers as saying or doing the wrong thing which might offend a learner or lead to emotional misunderstanding (DePalma \& Francis, 2014).

Mr. Jonathan, on multiple occasions, pointed out to me that there was a learner in 2016 that identified as homosexual. The learner asked the school management if she could attend the matric dance with her same-sex partner, but her request was denied. This creates a "hierarchy of inherited knowledge that privilege heterosexism 
and homophobia and the emotional attachments attached to such knowledge" (Reygan \& Francis, 2015: 115). This creates a socio-cultural distance between learners and the school who holds on to these values. Schools that share a tightly knit set of values often run the risk of developing organisations and cultures that are exclusionary. Teachers perpetuate hetreosexism and homophobia in school settings and they distance themselves, physically and pedagogically, from non-normative sexual and gendered bodies (Francis, 2013; Reygan \& Francis, 2015; Francis, 2017).

These norms are justified, by the school, as being Christian values and norms. The Christian religion reinforces and justifies inequalities in terms of gender and sexuality (DePalma \& Francis 2014). This is a characteristic of the apartheid system's approach to education; by adopting a Christian National Education with a dominant educational philosophy also known as Fundamental Pedagogics (Francis \& Hemson, 2011). At Hullbeck High, these values are reinforced through bible study in the mornings and a sermon during assembly (Note 16).

The school prides itself on being multi-cultural, with learners of different religions, ethnicities, and races forming part of the cohort. The celebration of this diversity takes place annually, on Multi-cultural Day. However, the issue herein lies with how this becomes a reflection of oppressive attitudes and structures (Soudien, 2004; Francis \& Hemson, 2011). The structure set by apartheid essentialised culture; "Fundamental Pedagogics strongly emphasised diversity in terms of race and ethnicity, within an unquestioned Christian commitment, while ignoring issues such as class" (Francis \& Hemson, 2011: 212). The term, multi-cultural, in itself is being used mainly of an essentialised understanding as a result from apartheid structures (Francis \& Hemson, 2011; DePalma \& Francis 2014). Therefore, the celebration of diversity becomes problematic and taken for granted as it does not celebrate difference but rather oppression. Multi-cultural Day becomes an event which celebrates racially-based cultural stereotypes instead of having resonance with the experience of its learners and the daily realities of South Africans; it becomes a celebration of that which falls outside of the norm. "It does not connect with the history of struggle and fails to challenge the idea of culture as static tradition" (Francis \& Hemson, 2011: 215).

\subsection{Sexual Harassment Faced by Women Teachers}

Teachers face situations where they feel as if their purpose is being threatened. Woman teachers are also more likely to face challenges in the space which include forms of harassment and/or discrimination. The situations Ms. Malik identified included "learners swearing to [her], learners that spit on [her], children who sexually harass [her]" (Note 17). She implied that these are realities faced by some teachers, not just at the school but in general, and that they should "take it as it comes".

Sexual harassment is defined as unwanted conduct of sexual nature which includes physical, verbal or non-verbal conduct (Prinsloo, 2006). This is explained as unequal treatment that impairs human dignity and is normally associated with the power to act (Prinsloo, 2006). This statement became true merely days later when, during one of my observations, a learner cat-called her, or one of the learners in the classroom:

... one learner enters freely [without knocking] and blows her a kiss. The class laughs at his action and the teacher sends him to the corner of the classroom highly irritated at his behaviour. She waits until the other learners leave to confront him. She reprimands him for his actions. She starts raising her voice at him and he comments on it. She states that he has disrespected her highly... as the class commented when he blew her a kiss. She asks "Lyk ek soos n pop vir jou?" [Do I look like a doll to you? Meaning, am I your play 'thing'? Alternatively, do you think I am stupid?]. He remains silent at her and she shakes her head at him (Observations, Ms. Malik classroom, 16/02/2017)

Ms. Malik could no longer maintain the 'facade' of suppressing her negative emotions. In this case, her duty to care and duty to maintain order came into conflict with each other and she uses harsh language to discipline the learner and to protect herself. She was also in constant negotiation with herself and her professional identity, i.e., maintaining the teacher self while still acknowledging that she exists outside of the school setting. It is reflections such as these where she attempted to redefine her boundaries as a teacher in relation to her bond with a specific learner (Winkler, 2002; Nias, 1986). The learner made it difficult for Ms. Malik to care - maintain that caring element. This also reveals the contradiction of care which is embedded in a heteronormative system in education. This incident reveals how difficult it is for teachers to maintain a caring element. More so, when a learner acts in such an aggressive and harassing manner.

\section{Conclusion}

This paper provided insight into the nature of interaction between teachers at learners at Hullbeck High, a former Model C school located in the Western Cape, South Africa. These interactions form a core part of the teaching experience and have proven, through other studies and my own, to be emotionally rewarding and professionally 
satisfying for teachers. In this regard, teachers' statuses rely heavily on their relationships with learners; considering their role as teachers always required some sort of reflection about their connection with learners and the health of these relationships. Emotions forms a part of the teaching experience and the expression thereof is dependent on the social context of the individual teacher's experience, the background of the individual, the actors in the space, the interactions between teachers and learners, and the rules of expression in the teaching space.

This paper focused on the rewarding aspects of teaching - the positive outcomes of emotional labour - while acknowledging the negative, as teachers suggest that fostering relationships with their learners outweigh the negative aspects of the profession. The emotional labour that teachers invest in their work contributes towards satisfaction with their jobs and provides a basis for the most rewarding aspect of teaching; the formation of bonds with learners. However, teachers do experience feelings of frustration.

By developing these bonds with the learners, a more effective teaching and learning process is facilitated. The intensity or closeness of these relationships is dependent on socio-cultural, moral, professional, physical and political closeness. Findings confirmed that distance in these aspects led to emotional misunderstanding between the two parties; which in turn contributed to a negative classroom climate, potentially hindering learning objectives. To ensure the effectiveness of these bonds, and to create emotional understanding between the teacher and the learner, teachers adopt three roles separate to that of actually teaching. Taking on these roles (coach, counsellor and parental figure) encourages greater emotional understanding between teachers and learners. This, in turn, promotes stronger relationships between the two and avoids the distance of certain emotional geographies, and can translate into improved dynamic within the classroom space. Not all teachers assume these three roles actively; even so, they do manifest in ways which teachers react to certain events, i.e., the counsellor role might be needed as a response to an emergency situation of a learner. Creating bonds with learners plays the biggest role in the teacher's attitude towards teaching and the learner's academic success. Cultivating this relationship over time makes for a deeper and personal relation between teachers and learner, and this has benefits for the teaching and learning process.

There are various challenges presented that can hinder the emotional understanding and bonds between teacher and learner. They include the classroom climate, sexual harassment, and negotiating the socio-cultural backgrounds of themselves, the school, and their learners.

\subsection{Implications for Policy}

Pedagogy and curriculum can explore how, and which, emotions can be drawn on in teaching and learning. Therefore, pre-service and in-service teacher training needs to incorporate the role of emotions and the ways in which this manifest inside and outside the classroom, when in contact with learners, as well as with colleagues. It is, therefore, important to discuss, analyse, and provide coping mechanisms for the ways in which their emotions manifest during teacher training - which they can use/incorporate after their training - analyse emotion rules, and importantly, the emotional labour that teachers invest in their profession. They need to ensure that felt emotions, negative or positive, are not suppressed to the point of stressful consequences (recognising the negative impact of emotional labour). In part of addressing emotions teachers' experience, this could become the stepping stone into dialogues that addresses prejudice and discrimination to ensure an environment that is inclusive. In addition to this, efforts need to be implemented where in-service and pre-service training educates teachers on culture as more than socio-historical realities. Teachers need to learn how to critically engage with cultural practices and perceptions and be provided the tools to do so. Stronger efforts need to be implemented for the benefit of the teacher and the learner in order to bridge the socio-cultural gaps that hinder emotional understanding between them. Policy makers would benefit from acknowledging these fundamental complexities in teaching and being a teacher. Acknowledgment of teachers' ongoing emotional struggles, rather than their compliance to policy and 'professional standards', will warrant a better environment for all agents involved in the schooling environment. Teachers are the agents who determine whether 'good schooling' occurs. In conclusion, teachers' emotional practices, in South Africa, require further critical, conceptually sound, and metaphorically rigorous attention from researcher across different disciplines.

\subsection{Limitations of My Study}

I acknowledge that there are limitations of my own research which can be taken for further study. Firstly, in the South African context, research was conducted at a former Model $\mathrm{C}$ school, which may have implications for teaching due to its history. The expressions and experiences may differ at, for example, a historically disadvantaged school. There are characteristics, such as cultural context, which can separate the two. This means that the three roles identified might not manifest in a different context. Secondly, the gender variable has not been taken into consideration in this research due to the focus of the research. Women are viewed as more caring due to 
their traditional role in society. Making gender the focus of future research could uncover the types of knowledge we produce regarding men and women (and other gender identities) (Note 18) who teach. Thirdly, the unit of analysis could be extended to learners and thus investigate whether learners' perspectives on their relationships with teachers complement or refute teachers' perspectives concerning interactions in the classroom, on school grounds, and outside school facilities. In addition, this investigation could interrogate where or not learners identify with the three roles teachers adopt.

\section{Acknowledgements}

I would like to thank the AW Mellon Foundation for providing the funding of my MA thesis on which this article is based on. As well as Dr Khayaat Fakier, my master's supervisor who provided me the guidance and strength throughout my academic journey.

\section{References}

Bourdieu, P. (2003). Social Reproduction. Culture: Critical Concepts in Sociology.

Brown, J., \& Dickinson, D. (2014). Sex education in a coloured South African township: Social challenges and pedagogical opportunities. In D. Francis (ed.) Sexuality, Society \& Pedagogy. SUN Press.

Denzin, N. (1984). On understanding emotion. San Francisco: Jossey-Bass.

DePalma, R., \& Francis, D. (2014). Silence, Nostalgia, violence, poverty ... : What does 'culture' mean for South African sexuality educators? Culture, Health \& Sexuality: An International Journal for Research, Intervention and Care.

Folbre, N. (2013). The Care Economy in Africa: Subsistence Production and Unpaid Care. Journal of African Economies, 23, 128-156. https://doi.org/10.1093/jae/ejt026

Forrester, G. (2005). All in a day's work: Primary teachers 'performing' and 'caring'. Gender and Education, 17(3), 271-287. https://doi.org/10.1080/09540250500145114

Foucault, M. (1976a). The History of Sexuality (Vol. 1). New York: Pantheon Books.

Foucault, M. (1976b). 'Lecture 11'. Society Must Be Defended. London: Picador.

Foucault, M. (1982). The Subject and Power, in H. Dreyfus \& P. Rabinow (eds.), Michel Foucault: Beyond Structuralism and Hermeneutics. Chicago: The University of Chicago Press. https://doi.org/10.1086/448181

Foucault, M. (1983). On the genealogy of ethics: An overview of work in progress, in H. Dreyfus, \& P. Rabinow (eds.), Michel Foucault: Beyond structuralism and hermeneutics (2nd ed., pp. 229-252). Chicago: The University of Chicago Press.

Francis, B., \& Skelton, C. (2001). Men Teachers and Construction of Heterosexual Masculinity in the Classroom. Sex and Education, 1(1), 9-21. https://doi.org/10.1080/14681810120041689

Francis, D. (2012). Teacher positioning on the teaching of sexual diversity in South African schools. Culture, Health \& Sexuality: An International Journal for Research, Intervention and Care, 14, 597-611. https://doi.org/10.1080/13691058.2012.674558

Francis, D. (2013). "You know the homophobic stuff is not in me, like us, it's out there". Using Participatory Theatre to challenge heterosexism and heteronormativity in a South African school. South African Journal of Education, 33(4)

Francis, D., \& Hemson, C. (2011). Multiculturalism in South Africa: In the Shadow of the Rainbow. In C. A. Grant \& A. Portera (eds.). Intercultural and multicultural education: enhancing global interconnectedness (pp. 211-224). New York: Routledge.

Gao, L. (1998). Cultural context of school science teaching and learning in the Peoples' Republic of China. Science Education, 82, 1-13. https://doi.org/10.1002/(SICI)1098-237X(199801)82:1<1::AID-SCE1>3.0.CO;2-L

Golby, M. (1996). Teachers' emotions: An illustrated discussion. Cambridge Journal of Education, 26. https://doi.org/10.1080/0305764960260310

Hargreaves, A. (2000). Mixed emotions: teachers' perceptions of their interactions with students. Teaching and Teacher Education, 16, 811-826. https://doi.org/10.1016/S0742-051X(00)00028-7

Hargreaves, A. (2001). Emotional geographies of teaching. Teachers College Record, 103, 1056-1080. https://doi.org/10.1111/0161-4681.00142

Hargreaves, A. (2005). Educational change takes ages: Life, career and generational factors in teachers' emotional 
responses to educational change. Teaching and Teacher Education, 21, 967-983. https://doi.org/10.1016/j.tate.2005.06.007

Hochschild, A. (1979). Emotion work, feeling rules, and social structure. American Journal of Sociology, 85(3), 551-575. https://doi.org/10.1086/227049

Hochschild, A. (1990). Ideology and emotion management: a perspective and path for future research, in T. Kemper (ed.), Research agendas in the sociology of emotions (pp. 117-142.). New York: SUNY Press.

Hochschild, A. R. (1983). The managed heart: Commercialization of human feeling. Berkeley: University of California Press

Hochschild, A. R. (2003). The Commercialization of Intimate Life: Notes from Home and Work. Berkeley: University of California Press.

Hochschild, A. R. (2011). Emotional Life on the Market Frontier. Annual Review of Sociology, 37, 21-33. https://doi.org/10.1146/annurev-soc-081309-150137

Hofmeyr, J. (2000). The emerging school landscape in post-apartheid South Africa. Unpublished paper for ISASA

Isenbarger, L., \& Zembylas, M. (2006). The emotional labour of caring in teaching. Teaching and Teacher Education, 22, 120-134. https://doi.org/10.1016/j.tate.2005.07.002

Kemper, T. D. (1993). Sociological models in the explanation of emotions, in M. Lewis \& J. Haviland (eds.). Handbook of emotions (pp. 41-51). New York: The Guilford Press.

Lareau, A. (2011). Unequal Childhoods: class, race and family life. Berkeley: University of California Press.

Lortie, D. C. (1975). Schoolteacher. Chicago: University of Chicago Press.

Maithufi, I. P. (1997). Children, young persons and the law. In: J. A. Robinson (ed.), The law of children and young persons in South Africa. Durban: Butterworths.

Meyer, D., \& Turner, J. (2006). Re-conceptualizing emotion and motivation to learn in classroom contexts. Educational Psychological Review, 18, 377-390. https://doi.org/10.1007/s10648-006-9032-1

Nias, J. (1989). Primary teachers talking. London: Routledge and Kegan Paul.

O'Connor, K. E. (2008). "You choose to care": teachers, emotions and professional identity. Teaching and Teacher Education, 24, 117-126. https://doi.org/10.1016/j.tate.2006.11.008

Oplatka, I. (2007). Managing emotions in teaching: toward an understanding of emotion displays and caring as nonprescribed role elements. Teachers College Record, 109, 1374-1400.

Ostrom, E. (2005). Understanding Institutional Diversity. Princeton University Press.

Ostrom, E. (2011). Background on the institutional analysis and development framework. Policy Studies Journal, 39(1), 7-27. https://doi.org/10.1111/j.1541-0072.2010.00394.x

Ostrom, O. (2010). Beyond markets and states: polycentric governance of complex economic systems. American Economic Review. p. 641-672. https://doi.org/10.1257/aer.100.3.641

Prinsloo, I. (2005). How safe are South African schools? South African Journal of Education, 25(1), 5-10.

Prinsloo, S. (2006). Sexual harrassment and violence in South African schools. South African Journal of Education, 26(2), 205-318.

Republic of South Africa. (1996). South African Schools Act no 84 of 1996. Retrieved from https://www.gdeadmissions.gov.za/Content/Files/SchoolsAct.pdf

Republic of South Africa. (1996). The Consitution of the Republic of South Africa. Retrieved from http://www.justice.gov.za/legislation/constitution/SAConstitution-web-eng.pdf

Reygan, F., \& Francis, D. (2015). Emotions and the pedagogies of discomfort: Teachers responses to sexual and gender diversity in the Free State, South Africa. Education as change, 19(1), 101-119. https://doi.org/10.1080/16823206.2014.943259

Soudien, C. (2004). 'Constituting the class': An analysis of the process of 'integration' in South African schools. Changing class: Education and social change in post-apartheid South Africa, 89-114

Steinberg, C. (2008). Assessment as an "emotional practice". English Teaching: Practice and Critique, 7(3), 42-64. 
Steinberg, C. (2013a). Teacher's emotions towards assessment: What can be learned from taking the emotions seriously? Unpublished doctoral dissertation. Johannesburg: University of Witwatersrand

Steinberg, C. (2013b). Teachers dealing with failure in a low socio-economic status school in South Africa, in C. Craig, P. Meijer \& J. Broeckmans (eds.), From Teacher Thinking to Teachers and Teaching: The evolution of a Research Community (Advances in Research on Teaching, Vol. 19). Emerald Group Publishing Limited.

Teeger, C. (2015). Ruptures in the Rainbow Nation: How desegregated South African schools deal with interpersonal and structural Racism. Sociology of Education, 88(3), 226-243. https://doi.org/10.1177/0038040715591285

Van Manen, M. (1990). Researching lived experience: Human science for an action sensitive pedagogy. New York: State University of New York Press.

Wharton, A. (2009). The Sociology of Emotional Labour. Annual Review of Sociology, 35, 147-165. https://doi.org/10.1146/annurev-soc-070308-115944

Winkler, G. G. (2002). Teacher Knowledge, Identity and Curriculum Reform. (Unpublished PhD thesis. United Kingdom: University of Nottingham).

Winograd, K. (2003). The functions of teachers' emotions: the good, the bad, and the ugly. Teachers College Record, 105(9), 1641-1673. https://doi.org/10.1046/j.1467-9620.2003.00304.x

Yin, H., \& Lee, J. (2012). Be passionate, but be rational as well: Emotional rules for Chinese teachers' work. Teaching and Teacher Educatio, 28, 56-65. https://doi.org/10.1016/j.tate.2011.08.005

Zembylas, M. (2002). "Structures of feeling" in curriculum and teaching: theorizing the emotional rules. Educational Theory, 52(2), 187-208. https://doi.org/10.1111/j.1741-5446.2002.00187.x

Zembylas, M. (2003). Emotions and teacher identity. Teachers and Teaching: Theory and Practice, 9, 213-238. https://doi.org/10.1080/13540600309378

Zembylas, M. (2004a). The emotional characteristics of teaching: An ethnographic study of one teacher. Teaching and Teacher Education, 20, 185-201. https://doi.org/10.1016/j.tate.2003.09.008

Zembylas, M. (2004b). Emotion metaphors and emotional labor in science teaching. Science Education, 88, 301-324. https://doi.org/10.1002/sce.10116

Zembylas, M. (2005). Discursive practices, genealogies, and emotional rules: a poststructuralist view on emotion and identity in teaching. Teaching and Teacher Education, 21, 935-948. https://doi.org/10.1016/j.tate.2005.06.005

Zhang, Q., \& Zhu, W. (2008). Exploring Emotion in Teaching: Emotional Labor, Burnout, and Satisfaction. Chinese Higher Education, Communication Education, 57(1), 105-122. https://doi.org/10.1080/03634520701586310

\section{Notes}

Note 1. All participants are referred to by pseudonyms.

Note 2 . The anonymity of the school is protected by giving it a pseudonym

Note 3. The quote, and information that follows, is provided on the school's website. Providing the reference of the website will expose the identity of the school; therefore, this has therefore been omitted.

Note 4. The school offers around fourteen sporting activities and around twelve cultural extra-mural activities.

Note 5. In South Africa, apartheid was a political and social system between 1948 and 1994 under the rule of the white minority-led government and promoted white supremacy. This led to racial segregation enforcing repressive legislation (Allen, 2005). This logic classified one as either 'Black', 'White', 'Coloured' or 'Indian' which was used to describe one's essential being (Crapanzano, 1985).

Note 6. Republic of South Africa. Employment of Educators Act. No 76 of 1998 [Online]. Available: http://www.education.gov.za/Portals/0/Documents/Legislation/Acts/EMPLOYMENT\%20OF\%20EDUCATORS \%20ACT,\%20NO\%2076\%20OF\%201998,\%2027\%2010\%202011.pdf?ver=2015-01-30-102238-007

Note 7. Interview Ms. Malik, 09/02/2017.

Note 8. Observations Mr. Jonathan, Matric quad, 07/02/2017. 
Note 9. Observations Mr. Jonathan, Old school hall, 07/02/2017.

Note 10. Observations Ms Abrahams, 08/02/2017; Interview Ms Malik, 09/02/2017, Observations Mr. Jonathan, Old hall, 07/02/2017, Interview Mr Jonathan, 02/11/2016.

Note 11. Interview Ms Malik, 09/02/2017.

Note 12. Interview Ms. Conley, 14/02/2017.

Note 13. Interview Ms Abrahams, 21/02/2017.

Note 14. Interview Ms. Abrahams, 21/02/2017.

Note 15. The word 'bond' came up a lot during my discussions with the teachers or in our interviews, which led me to use the word to describe the relationships that teachers have with learners.

Note 16. The South Gauteng High Court has ruled to ban the promotion of one religion over others as it leads to the exclusion of others (See Rahlaga, M. 2017. Court to rule on banning religious practices in schools [Online]. Available:

http://ewn.co.za/2017/06/28/judgment-to-be-handed-down-in-application-banning-religion-practices-in-schools [2017, September 18]. This ruling has came to being after I concluded my fieldwork.

Note 17. Interview Ms. Malik, 09/02/2017.

Note 18. The emotional experience of other gender and sexual identities, as well as non-conforming bodies, could be included for further studies; this could also consider race and class variables.

\section{Copyrights}

Copyright for this article is retained by the author(s), with first publication rights granted to the journal.

This is an open-access article distributed under the terms and conditions of the Creative Commons Attribution license (http://creativecommons.org/licenses/by/4.0/). 